\author{
Ying Zhang ${ }^{1}$ \\ Zhenbo Lv ${ }^{1}$ \\ Bo Guan ${ }^{2}$ \\ Yuanjin Liu ${ }^{1}$ \\ Fan $\mathrm{Li}^{1}$ \\ Shaowen $\mathrm{Li}^{1}$ \\ Yuanqing $\mathrm{Ma}^{1}$ \\ Junbao $\mathrm{Yu}^{2}$ \\ Yunzhao $\mathrm{Li}^{2}$ \\ ${ }^{1}$ Shandong Key Laboratory of Marine \\ Ecological Restoration, Shandong \\ Marine Fisheries Research Institute, \\ Yantai, Shandong, P. R. China \\ ${ }^{2}$ Key Laboratory of Coastal Zone \\ Environmental Processes and \\ Ecological Remediation, Yantai \\ Institute of Coastal Zone Research \\ (YIC), Chinese Academy of Sciences \\ (CAS), Shandong Provincial Key \\ Laboratory of Coastal Zone \\ Environmental Processes, YICCAS, \\ Yantai, Shandong, P. R. China
}

\section{Research Article Status of Macrobenthic Community and Its
Relationships to Trace Metals and Natural
Sediment Characteristics}

Laizhou Bay, located in the northwest of Shandong Peninsula, has complex transitional environments between terrestrial and marine ecosystems. In the present study, a total of 122, 131, and 139 species were collected in spring, summer, and autumn 2011, respectively. Species constitutions of macrobenthos were grouped into four phyla, of which annelida were the most abundant phylum, the average biomass proportion of echinodermata was the lowest, and the proportion of important species for mollusca was the highest. The structure of the macrobenthic community showed significant differences between sites, and greater divergence was observed between the third site (S03) and other stations. The ABC plots showed that the biomass curve lay below the abundance curve, and the $W$-statistic value was negative. The result of the BOPA index showed that two stations had moderate ecological status in spring and that there were two heavily polluted sites and one moderately polluted site in summer. The BIO-ENV analyses indicated that the grain-size fractions together with trace metals $(\mathrm{Hg}, \mathrm{Pb}, \mathrm{Zn}$, $\mathrm{Cu}$, and $\mathrm{Cr}$ ) could be considered as the major environmental variables influencing the macrobenthic patterns. The results together demonstrated that the macrobenthic communities in Laizhou Bay were negatively affected, perhaps by the tremendous impact of heavy metals in the sediments.

Keywords: Amphipods; Biological indicator; Heavy metal; Laizhou Bay; Polychaetes

Received: October 20, 2012; revised: December 5, 2012; accepted: December 10, 2012

DOI: $10.1002 /$ clen.201200575

\section{Introduction}

Soft-bottom macrobenthos is an important ecological group. It plays important roles in material cycling and energy flow in marine ecosystems [1]. The macrobenthic fauna provides direct food sources for economically important aquatic animals, and is a key link in the food chain. Macrobenthic animals live at the sea bottom, where they interact with the marine environment through feeding, digging and building tubes. In addition, they are relatively sedentary and have long life spans, subjecting them to long-term exposure to different sources of disturbance and pollutants of both natural and human origins [2, 3]. They have been widely introduced as biological indicators of habitat conditions in marine and estuarine environments to assess water quality and ecological risk assessments for their physiological sensitivity [4-6].

As environmental pollution or anthropogenic disturbance increases, macrobenthic communities are dominated by a few highly abundant opportunities species. Polychaetes, often linked

Correspondence: Dr. B. Guan, Key Laboratory of Coastal Zone Environmental Processes and Ecological Remediation, Yantai Institute of Coastal Zone Research (YIC), Chinese Academy of Sciences (CAS), Yantai 264003, Shandong, P. R. China

E-mail: guanb627@yahoo.cn

Abbreviations: ABC, abundance biomass comparison; BOPA, benthic opportunistic polychaetes amphipods index; IRI, index of relative importance; nMDS, non-metric multidimensional scaling in the past to the concept of opportunistic species, have played an especially important role in impacted soft-bottom habitats. They are frequently used as biological indicators of environmental disturbance. Capitella capitata, a representative opportunistic polychaete, is short lived, matures rapidly and has a high reproductive output. Planktonic and macrobenthic larvae are both food supplements for C. capitata, which can develop in great quantities in a short period of time and play a major role in macrobenthic community succession in soft-bottom habitats [6, 7]. Amphipods build and irrigate their burrows or tubes in previously anoxic sediment, creating small oxidized cylinders within the sediment that allow sea-bottom oxygenation and nitrification processes. Amphipods have been termed "structural" species and credited on different occasions as good bio-indicators of environmental recovery [8].

The macrobenthic species constitutions and spatial distribution are closely related to their survival in the environment $[9,10]$. Variability in water depth, salinity, sediment characteristics, plankton density, and anthropogenic disturbance can cause changes in macrobenthic species distribution and biodiversity, and provides diverse habitats of macrobenthos [11-13]. Physical disturbance of sediment and heavy-metal contamination may have significant impacts on macrobenthic composition in coastal water. Laizhou Bay, located in the northwest of Shandong Peninsula, is a semienclosed marine region. Coastal rivers carry ecologically destructive levels of pollutants into Laizhou Bay. Moreover, the bay supports industrial activities, salt extraction, and an aquaculture farm, which have resulted in a cumulative burden of various environmental 
stresses [14]. However, the impact of sediment characteristics and heavy-metal contamination on the macrobenthos in Laizhou Bay is actually unknown. In this context, the present study aimed to identify the macrobenthic constitutions, spatial distribution, and correlation with trace metals, natural sediment characteristics and the macrobenthic community, which were important to evaluate the quality of ecological environment in Laizhou Bay, and could provide basic scientific information for environmental pollution control and marine ecological protection.

\section{Materials and methods}

\subsection{Study area}

Twenty-nine sampling stations (S1-S29) were located at latitudes $37^{\circ} 12^{\prime}$ to $38^{\circ} 0^{\prime} \mathrm{N}$ and longitudes $119^{\circ} 12^{\prime}$ to $119^{\circ} 40^{\prime} \mathrm{E}$ in Laizhou Bay (Fig. 1).

\subsection{Macrobenthic sampling}

Sampling was undertaken in May, August, and October 2011 representing spring, summer, and autumn, respectively. Four replicates were taken at each site using a Van Veen grab $\left(0.05 \mathrm{~m}^{2}\right)$. Three replicates were sieved through a $0.5-\mathrm{mm}$ mesh screen, and fixed in $10 \%$ buffered formalin, and then preserved in $4 \%$ formalin for subsequent macrobenthos sorting. Macrobenthos were sorted to the lowest possible taxonomic levels and counted. The fourth replicate was used for analysis of sediment characteristics.

\subsection{Sediment characteristics}

Geochemical analysis was performed after sediment homogenization. Part of the sediment from each sample was dried to $80^{\circ} \mathrm{C}$ until a constant weight was found and then ground to a fine powder. The organic matter content (LOI) was determined by "loss on ignition" of dried sediment at $450^{\circ} \mathrm{C}$ for $4 \mathrm{~h}$ [15]. Grain-size analysis was performed by laser particle-size analysis (Malvern, UK). The sediments were divided into four fractions: medium sand (500$250 \mu \mathrm{m})$, fine sand $(250-63 \mu \mathrm{m})$, fine silt $(63-4 \mu \mathrm{m})$, and clay $(4-1 \mu \mathrm{m})$.

Sediments used in metal analysis were previously $\mathrm{HNO}_{3}$-cleaned at least $24 \mathrm{~h}$, and then rinsed for three times with deionized water. After drying, $0.5 \mathrm{~g}$ of sediment was weighed and digested by microwave in high-pressure Teflon vessels. Atomic absorption spectroscopy with flame atomization was used to assay relevant metal contents $(\mathrm{Hg}, \mathrm{Cu}, \mathrm{Pb}$, and $\mathrm{Cr})$ in $10 \mathrm{~mL}$ of supra-pure concentrated nitric acid [16].

\subsection{Data analysis}

The index of relative importance (IRI) was calculated for species dominance. The hierarchical clustering, un-weighted pair group

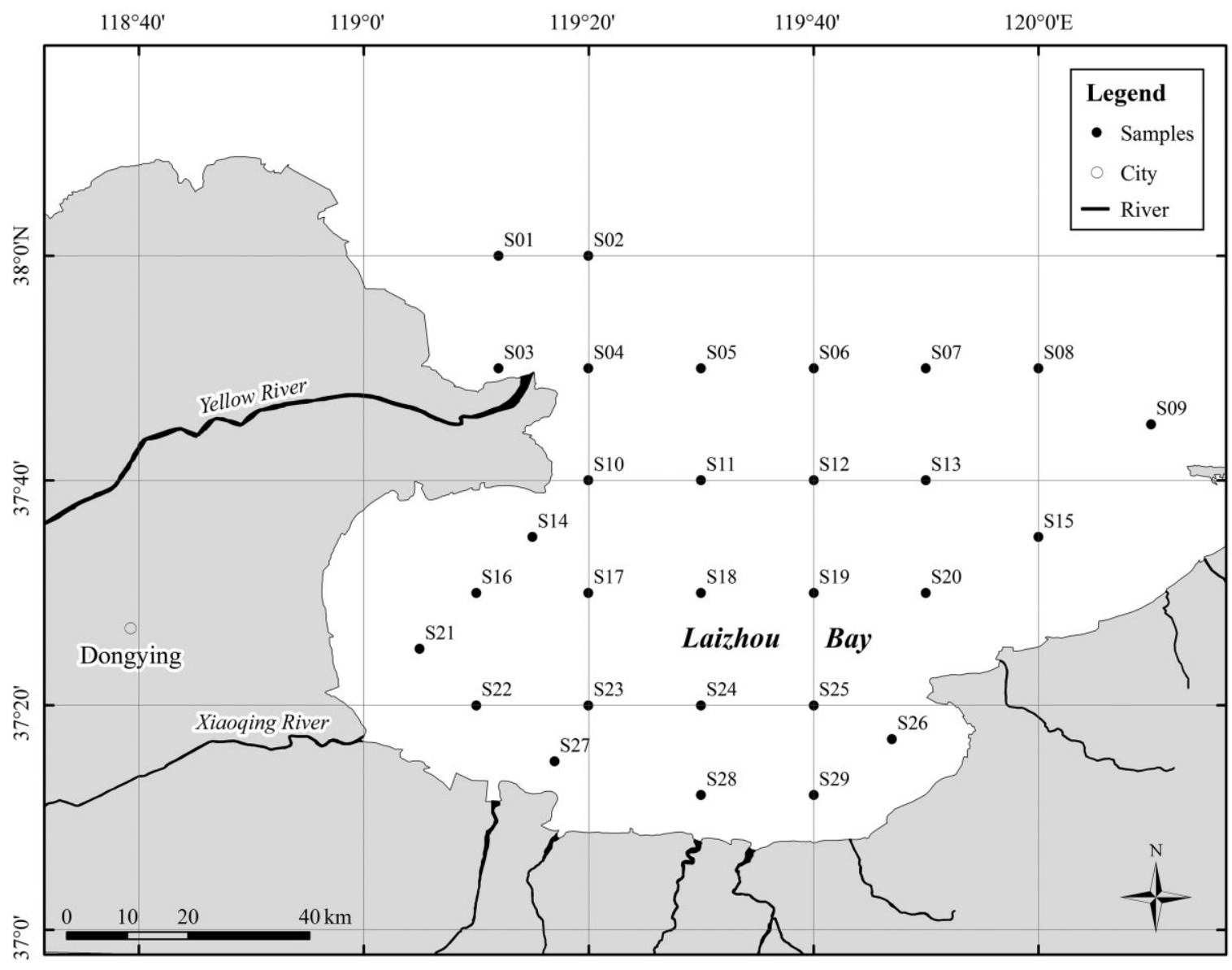

Figure 1. Map of Laizhou Bay showing sampling stations. 
method with arithmetic mean (UPGMA), and non-metric multidimensional scaling (nMDS) approaches generated by PRIMER software (Plymouth routines in multivariate ecological research) were used to analyze the pattern of community compositions $[17,18]$.

Abundance biomass comparison $(\mathrm{ABC})$ curves and $\mathrm{W}$-statistic were used to analyze the disturbed states [19]. In undisturbed states, the community was assumed to be dominated by $k$-selected species that were slow-growing, large, and late maturing. It was also assumed that the biomass curve lay above the abundance curve, and that the $W$-statistic value was positive. Intersection was found between the abundance curves and the biomass curves, indicating current macrobenthic community were moderately disturbed. With increasing disturbance, $r$-selected species (fast-growing, small, opportunistic) represented a large proportion of the macrobenthic community, the biomass curve would lie below the abundance curve, and the $W$-statistic value was negative.

The benthic opportunistic polychaetes amphipods index (BOPA) was introduced to assess ecological quality status of Laizhou Bay [20]. This index is:

BOPA index $=\log \left(\frac{f_{\mathrm{p}}}{f_{\mathrm{A}}+1}\right)$

where $f_{\mathrm{P}}$ is the ratio of numbers of opportunistic polychaetes to all the numbers of samples, and $f_{\mathrm{A}}$ is the ratio of numbers of amphipod excluding Jassa amphipods to all the numbers of samples. The BOPA index ranges were to define five ecological quality status classes: $0.0-0.04576$ for uncontaminated sites, $0.04576-0.13966$ for slightly contaminated sites, $0.13966-0.19382$ for moderately contaminated, $0.19382-0.26761$ for heavily contaminated sites, and $0.26761-0.30103$ for extremely contaminated or azoic sites.
The BIO-ENV index was employed to analyze the correlations between the macrobenthic community and environmental variables, and the Spearman rank correlation coefficient $\left(\rho_{\mathrm{s}}\right)$ could measure the best matches of environmental factors to affect macrobenthic community.

\section{Results}

\subsection{Macrobenthic community composition and structure}

A total of 122,131, and 139 species were collected in spring, summer, and autumn, respectively, in Laizhou Bay. A total of 122 species, including 48 species of annelida, 46 species of mollusca, 22 species of arthropoda, and 4 species of echinodermata, were recorded in spring. There were 47 species of annelida, 46 species of mollusca, 30 species of arthropoda, and 4 species of echinodermata recorded in summer. In autumn, 52 species of annelida, 43 species of mollusca, 33 species of arthropoda, and 2 species of echinodermata were identified (Table 1). Species constitutions of macrobenthos were grouped into four phyla, of which annelida was the most abundant phylum, followed by mollusca, arthropoda, and echinodermata.

The average biomass values of the community in spring, summer, and autumn were $11.23,15.15$, and $14.96 \mathrm{~g} \mathrm{~m}^{-2}$, respectively (Table 2). The average biomass values of mollusca were 5.66, 8.64, and $6.24 \mathrm{~g} \mathrm{~m}^{-2}$ in spring, summer, and autumn, respectively, making them the largest contributor to the biomass of the macrobenthos. There were $0.83,0.71$, and $0.77 \mathrm{~g} \mathrm{~m}^{-2}$ in average biomass of echinodermata in spring, summer, and autumn, respectively. The proportion of echinodermata was the lowest in summer and autumn, around $5 \%$.

To further understand the composition of the macrobenthic community in Laizhou Bay, the IRI was calculated. Table 3 shows

Table 1. Species constitutions of macrobenthos in Laizhou Bay

\begin{tabular}{|c|c|c|c|c|c|c|}
\hline \multirow{2}{*}{$\frac{\text { Seasons }}{\text { Species }}$} & \multicolumn{2}{|c|}{ Spring } & \multicolumn{2}{|c|}{ Summer } & \multicolumn{2}{|c|}{ Autumn } \\
\hline & Numbers & Proportion/\% & Numbers & Proportion/\% & Numbers & Proportion/\% \\
\hline Annelida & 48 & 39.34 & 47 & 35.88 & 52 & 37.41 \\
\hline Mollusca & 46 & 37.70 & 46 & 35.11 & 43 & 30.94 \\
\hline Arthropoda & 22 & 18.03 & 30 & 22.90 & 33 & 23.74 \\
\hline Echinodermata & 4 & 3.2 & 4 & 3.05 & 2 & 1.44 \\
\hline Others & 2 & 1.64 & 4 & 3.05 & 9 & 6.47 \\
\hline Total & 122 & 100 & 131 & 100 & 139 & 100 \\
\hline
\end{tabular}

Table 2. Species biomass constitutions of macrobenthos in Laizhou Bay $\left(\mathrm{g} \mathrm{m}^{-2}\right)$

\begin{tabular}{|c|c|c|c|c|c|c|}
\hline \multirow{2}{*}{$\frac{\text { Seasons }}{\text { Species }}$} & \multicolumn{2}{|c|}{ Spring } & \multicolumn{2}{|c|}{ Summer } & \multicolumn{2}{|c|}{ Autumn } \\
\hline & Biomass & Proportion/\% & Biomass & Proportion/\% & Biomass & Proportion/\% \\
\hline Annelida & 3.58 & 31.88 & 2.84 & 18.75 & 2.68 & 17.91 \\
\hline Mollusca & 5.66 & 50.40 & 8.64 & 57.03 & 6.24 & 41.71 \\
\hline Arthropoda & 0.78 & 6.95 & 1.57 & 10.36 & 3.81 & 25.47 \\
\hline Echinodermata & 0.83 & 7.39 & 0.71 & 4.69 & 0.77 & 5.15 \\
\hline Others & 0.38 & 3.38 & 1.40 & 9.24 & 1.45 & 9.69 \\
\hline Total & 11.23 & 100 & 15.15 & 100 & 14.96 & 100 \\
\hline
\end{tabular}


Table 3. Important components of dominant species in the study area

\begin{tabular}{|c|c|c|c|c|c|c|c|c|c|}
\hline \multirow[t]{2}{*}{ Species } & \multicolumn{3}{|c|}{ Spring } & \multicolumn{3}{|c|}{ Summer } & \multicolumn{3}{|c|}{ Autumn } \\
\hline & $w(\%)$ & $n(\%)$ & IRI & $w(\%)$ & $n(\%)$ & IRI & $w(\%)$ & $n(\%)$ & IRI \\
\hline Alvenius ojianus & 6.06 & 55.33 & 3386.91 & 14.88 & 69.45 & 5234.72 & & & \\
\hline Leptomya minuta & 1.21 & 11.28 & 430.51 & & & & & & \\
\hline Sternaspis sculata & 2.93 & 2.31 & 361.39 & 1.58 & 0.42 & 117.31 & 0.98 & 1.25 & 130.60 \\
\hline Neverita didyma & 11.42 & 0.10 & 357.63 & 4.26 & 0.34 & 365.52 & 6.21 & 0.84 & 486.51 \\
\hline Lumbrineris heteropoda & 13.68 & 0.04 & 236.61 & 6.47 & 0.01 & 111.88 & & & \\
\hline Glycinde gurjanovae & 0.81 & 1.29 & 188.11 & 0.52 & 1.83 & 227.35 & 0.26 & 4.38 & 399.94 \\
\hline Moerella jedoensis & 6.03 & 0.10 & 169.15 & 4.11 & 0.63 & 359.66 & 2.89 & 2.69 & 365.92 \\
\hline Siliqua pulchella & 2.00 & 12.15 & 146.39 & & & & & & \\
\hline Moerella iridescens & 2.18 & 0.81 & 133.52 & 4.15 & 0.49 & 207.89 & 2.02 & 1.96 & 233.22 \\
\hline Theora lata & 1.478 & 1.10 & 115.43 & 3.19 & 0.20 & 199.02 & & & \\
\hline Paraprionospio pinnata & 0.198 & 1.87 & 113.58 & & & & & & \\
\hline Leptochela gracilis & 3.54 & 0.10 & 113.05 & & & & 1.44 & 0.63 & 107.01 \\
\hline Capitella capitata & 0.30 & 1.68 & 109.46 & & & & & & \\
\hline Musculus senhousia & & & & 3.48 & 11.04 & 500.68 & & & \\
\hline Cirratulus cirratus & & & & 3.04 & 2.32 & 425.56 & & & \\
\hline Amaeana occidentalis & & & & 2.43 & 1.27 & 216.46 & 2.15 & 1.38 & 133.76 \\
\hline Philine kinglipini & & & & 1.87 & 0.47 & 201.67 & & & \\
\hline Ringicula doliaris & & & & 2.25 & 0.85 & 192.38 & 1.78 & 1.91 & 203.62 \\
\hline Nassarius semiplicatus & & & & 3.43 & 0.14 & 147.66 & & & \\
\hline Philyra pisum & & & & 2.89 & 0.15 & 104.80 & & & \\
\hline Mesochaetopterus japonicus & & & & & & & 2.69 & 26.46 & 804.14 \\
\hline Dosinia japonica & & & & & & & 11.27 & 0.89 & 251.72 \\
\hline Sthenolepis japonica & & & & & & & 0.44 & 2.10 & 192.29 \\
\hline Eucrate creneta & & & & & & & 7.53 & 0.13 & 158.39 \\
\hline Protankyra bidentata & & & & & & & 5.04 & 4.38 & 129.98 \\
\hline
\end{tabular}

the dominant and important species in spring, summer, and autumn. In spring and summer, Alvenius ojianus was definitely the dominant species, and the IRI values were 3386.91 and 5234.72, respectively. In spring, the important species included mollusca Leptomya minuta, Neverita didyma, Moerella jedoensis, Siliqua pulchella, Moerella iridescens, and Theora lata, annelida Sternaspis sculata, Lumbrineris heteropoda, Glycinde gurjanovae, Paraprionospio pinnata, and Capitella capitata, and arthropoda Leptochela gracilis. In summer, the proportion of important species for mollusca at $57.1 \%$ was the highest, followed by $35.71 \%$ for annelida, and there was only one important arthropoda species, Philyra pisum. There were 13 important species in autumn, including 5 species of annelida, 5 of mollusca, 2 of arthropoda, and 1 of echinodermata.

Clustering and nMDS, based on Bray-Curtis similarities from fourth-root transformed abundance, clearly showed that the community structure of the macrobenthos in Laizhou Bay differed significantly between sites (Fig. 2). Another obvious feature of the clustering and nMDS plot was the greater divergence between the third site (S3) and other stations. Therefore, to explore the manner of macrobenthic community at different stations, it is meaningful to evaluate the relationship between the differences and various amounts of sediment disturbance and heavy-metal pollutions.

\subsection{Assessment of macrobenthic community health}

The ABC plots for Laizhou Bay show that the biomass curves lay below the abundance curves and the $W$-statistic value was negative
(Fig. 3), indicated that the macrobenthic community experienced disturbed conditions and was dominated by smaller $r$-selected or opportunistic species.

The result of the BOPA index showed that two stations had moderate ecological status in spring, that there were two heavily and one moderately polluted sites in summer, and that $90 \%$ of the stations had high ecological quality status in autumn (Fig. 4). In spring, low colonization by amphipods (35 ind $\mathrm{m}^{-2}$ at station $\mathrm{S} 24$ and 10 ind m$^{-2}$ at station S25) and abundance of opportunistic polychaetes C. capitata $\left(215\right.$ ind $\mathrm{m}^{-2}$ at station S24 and 260 ind $\mathrm{m}^{-2}$ at station S25) and P. pinnata (230 ind $\mathrm{m}^{-2}$ at station $\mathrm{S} 25$ ) were observed at the moderately polluted sites. In summer, a very high abundance of opportunistic polychaetes C. cirratus (3320 ind $\mathrm{m}^{-2}$ at station S23), and an abundance of opportunistic polychaetes Heteromastus filiforms (140 ind $\mathrm{m}^{-2}$ at station S4 and 270 ind $\mathrm{m}^{-2}$ at station S2) were detected.

\subsection{Sediment characteristics}

The sediment was sorted into medium sand $(500-250 \mu \mathrm{m})$, fine sand $(250-63 \mu \mathrm{m})$, fine silt $(63-4 \mu \mathrm{m})$, and clay $(4-1 \mu \mathrm{m})$. Textural types such as fine silt, silty sand, and sandy silt were observed in Laizhou Bay with varied levels of the four textural grades of medium sand, fine sand, fine silt, and clay mixture (Fig. 5). Medium sand existed only at stations S3, S8, and S17, and the proportions were $0.97,0.80$, and $0.32 \%$, respectively. The proportion of fine sand at station S23 was $56.28 \%$, the highest found at any of the stations. The proportion of fine silt was the highest at station S24 (97.42\%). 

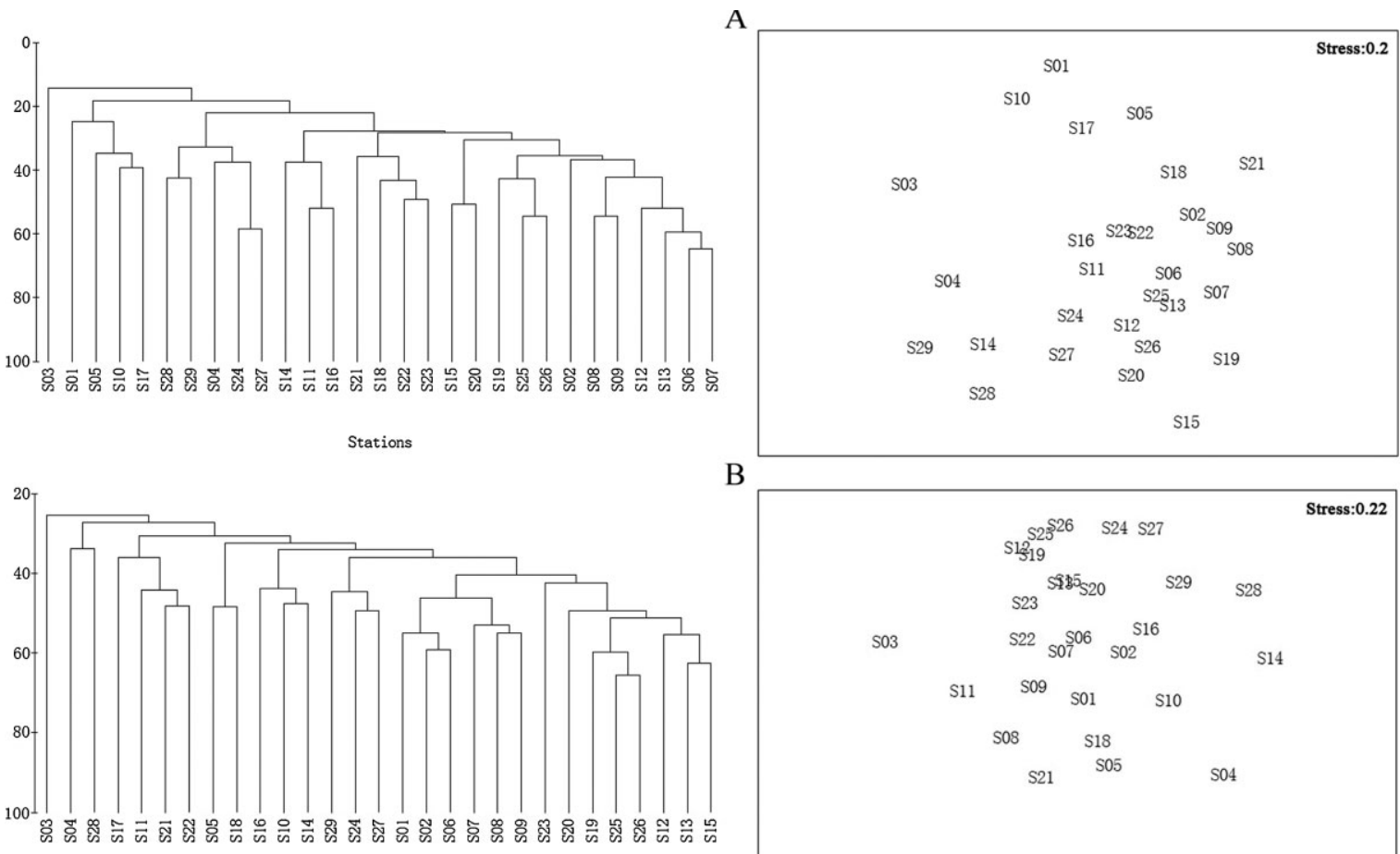

B
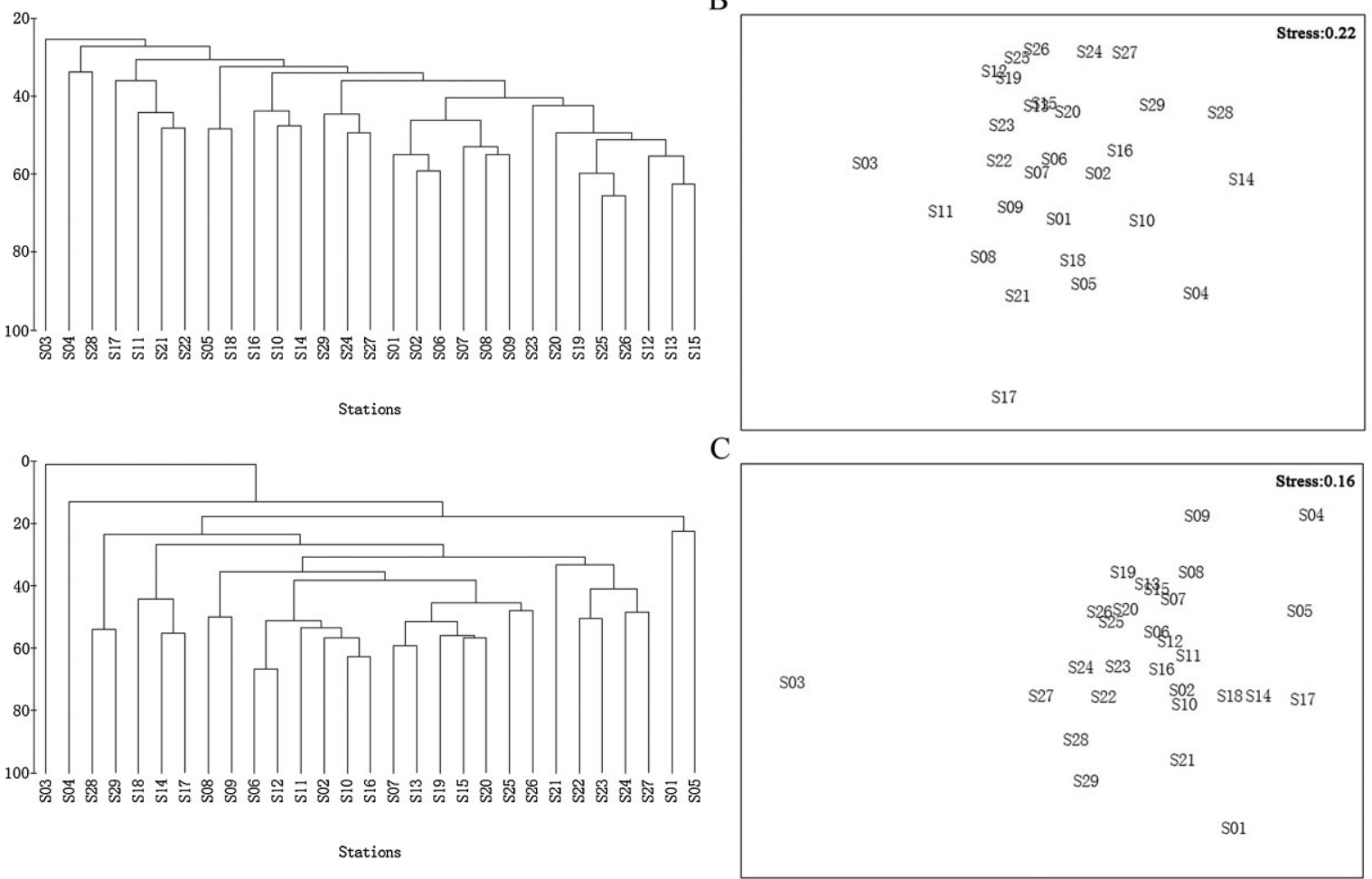

Figure 2. Macrobenthic community types of the sampling stations based on cluster (left) and nMDS (right), using group-average linking of Bray-Curtis similarities calculated on fourth root-transformed abundance data, (A) in spring, (B) in summer, and (C) in autumn. Numbers indicate station labels.

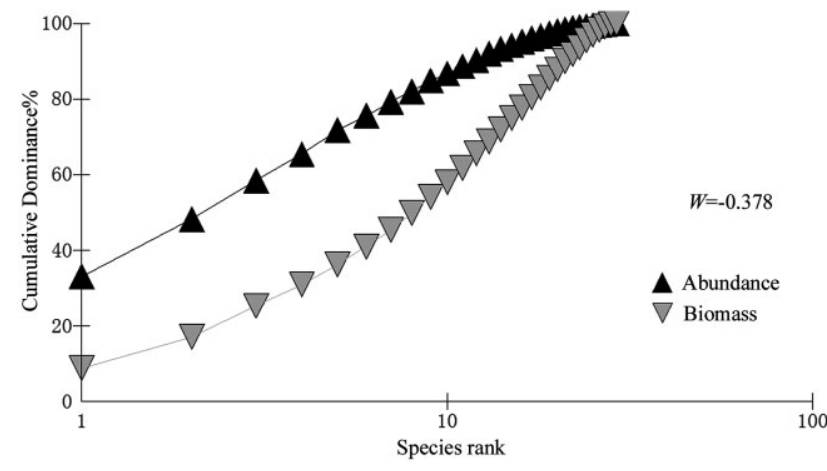

Figure 3. $A B C$ plot drawn based on the abundance and biomass of macrobenthic in Laizhou Bay.

\subsection{Relationship between environmental and biological variables}

The BIO-ENV index was employed to analyze the combinations of environmental variables that were best matches to affect macrobenthic community structure. The single environmental factor that best matched the macrobenthic community was grain size fraction $250-63 \mu \mathrm{m}\left(\rho_{\mathrm{s}}=0.473\right)$, followed by $\mathrm{Pb}\left(\rho_{\mathrm{s}}=0.403\right)$, and $\mathrm{Hg}\left(\rho_{\mathrm{s}}=0.389\right)$ in spring. The combination of these three variables with $\mathrm{Zn}$ and medium sand $(500-250 \mu \mathrm{m})$ constituted the overall optimum $\left(\rho_{\mathrm{s}}=0.867\right)$. The BIO-ENV analyses in summer showed that the fine sand $(250-63 \mu \mathrm{m})$ content of the sediment had the highest correlation with the macrobenthic patterns. The matches of environmental variables $(\mathrm{Hg}, \mathrm{Cu}, \mathrm{Pb}$, medium sand, and fine silt) best explained the macrobenthic composition. In autumn, organic carbon, $\mathrm{Pb}$, $\mathrm{Cr}$, medium sand, and fine sand constituted the combination 


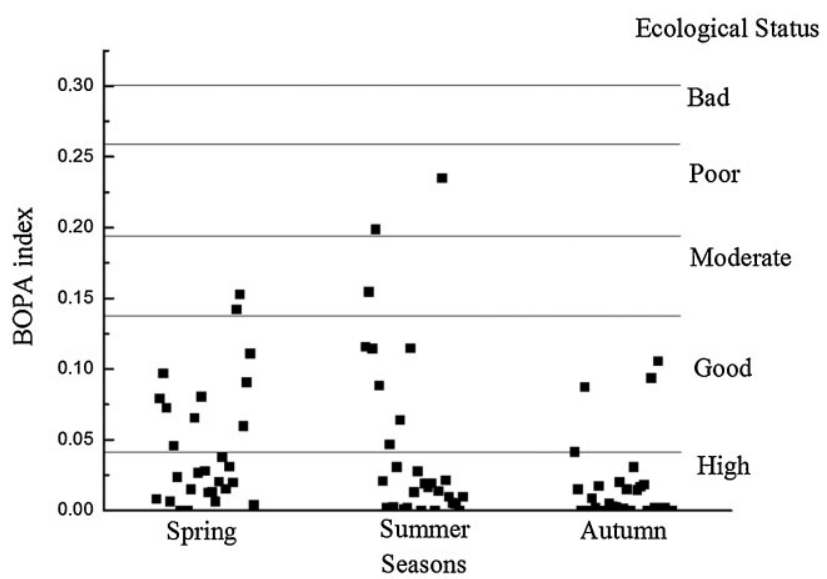

Figure 4. BOPA index calculated for the stations in spring, summer, and autumn.

of parameters that gave the highest rank correlation value $\left(\rho_{\mathrm{s}}=0.848\right.$; Table 4). Although the BIO-ENV method did not give direct correlations between marine environmental variables and the macrobenthos, the possible environmental variables affecting the macrobenthic community patterns was identified and could be applied to assess water quality in ecological risk assessment of Laizhou Bay.

\section{Discussion}

\subsection{Characteristics of macrobenthos in Laizhou Bay}

The composition and structure of the macrobenthic community is one of the indicated biological quality elements to be used in transitional and coastal waters for quality status assessment [21]. Species constitutions of the macrobenthos in Laizhou Bay were grouped into four phyla, of which annelida was the most abundant phylum, followed by mollusca, arthropoda, and echinodermata (Table 1). The contribution of mollusca to the average macrobenthic biomass was the highest, and the contribution of echinodermata was the lowest in summer and autumn, only around 5\% (Table 2). According to the macrobenthic data for 1982, the proportion of total biomass attributable to annelida was the lowest throughout the year, and the proportions attributable to echinodermata were 51.12 and $90.16 \%$ in summer and autumn, respectively, the highest contributions of all the four phyla [22]. Therefore, the macrobenthic community composition in Laizhou Bay has undergone a tremendous change in the past three decades.

The dominance shifts are likely a direct result of anthropogenic stressors [6]. The important phyla of Laizhou Bay were mainly mollusca and annelida in 2011 (Table 3), whereas mollusca and echinodermata were dominant in 1982 [22]. The polychaeta of

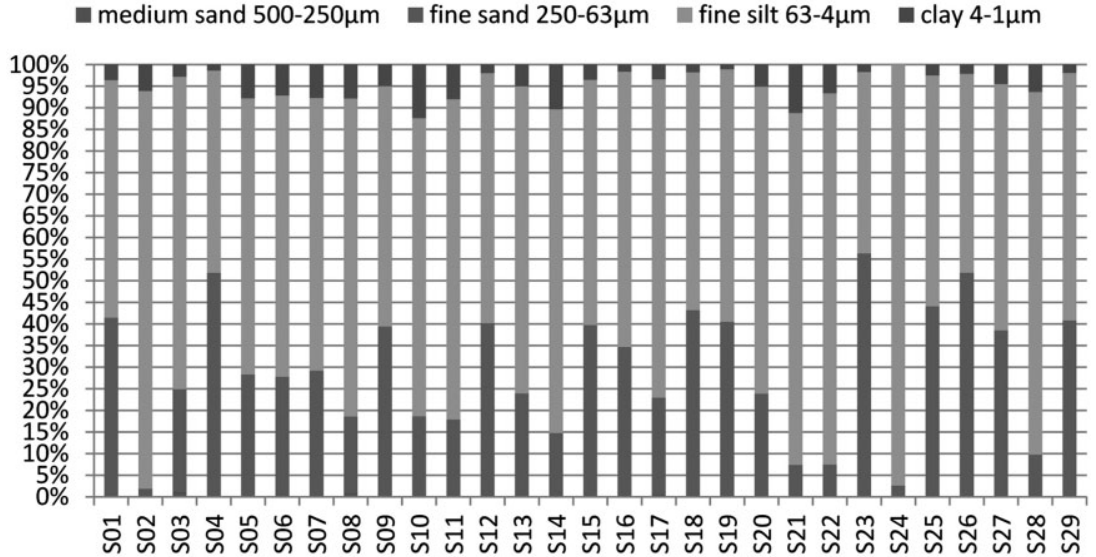

Figure 5. Sediment texture in Laizhou Bay. Numbers indicate station labels.

Table 4. Summary of results from BIO-ENV analyses of 29 stations in Laizhou Bay

\begin{tabular}{|c|c|c|}
\hline Spring & Summer & Autumn \\
\hline Organic carbon $(0.257)$ & Organic carbon $(0.182)$ & Organic carbon $(0.255)$ \\
\hline Sulfide (0.199) & Sulfide $(0.004)$ & Sulfide $(0.369)$ \\
\hline Petroleum (0.359) & Petroleum (0.320) & Petroleum (0.315) \\
\hline $\mathrm{Hg}(0.389)$ & $\mathrm{Hg}(0.394)$ & $\mathrm{Hg}(0.195)$ \\
\hline $\mathrm{Cu}(0.241)$ & $\mathrm{Cu}(0.444)$ & $\mathrm{Cu}(0.295)$ \\
\hline $\mathrm{Pb}(0.403)$ & $\mathrm{Pb}(0.437)$ & $\mathrm{Pb}(0.291)$ \\
\hline $\operatorname{Zn}(0.251)$ & $\operatorname{Zn}(0.484)$ & $\operatorname{Zn}(0.168)$ \\
\hline $\mathrm{Cr}(0.326)$ & $\mathrm{Cr}(0.252)$ & $\mathrm{Cr}(0.328)$ \\
\hline Medium sand (0.339) & Medium sand $(0.299)$ & Medium sand $(0.322)$ \\
\hline Fine sand $(0.473)$ & Fine sand (0.486) & Fine sand (0.505) \\
\hline Fine silt $(0.311)$ & Fine silt $(0.417)$ & Fine silt $(0.347)$ \\
\hline Clay $(0.261)$ & Clay (0.271) & Clay (0.236) \\
\hline Max. correlation: & Max. correlation: & Max. correlation: \\
\hline $\begin{array}{l}\mathrm{Hg}, \mathrm{Pb}, \mathrm{Zn} \text {, medium sand, } \\
\text { fine sand }(0.867)\end{array}$ & $\begin{array}{l}\mathrm{Hg}, \mathrm{Cu}, \mathrm{Pb}, \text { medium sand, } \\
\text { fine silt }(0.852)\end{array}$ & $\begin{array}{l}\text { Organic carbon, } \mathrm{Pb}, \mathrm{Cr}, \text { medium sand, } \\
\text { fine sand }(0.848)\end{array}$ \\
\hline
\end{tabular}


annelida have substituted for echinodermata as important colonies in the past three decades. In spring, the important species included polychaeta $P$. pinnata and C. capitata, which have been referred to as opportunistic species [23]. The rapid development, rapid mature and high reproductive output of opportunistic polychaetes facilitated their ability to quickly colonize them in great abundances [24, 25]. Polychaetes, often linked in the past to the concept of opportunistic species able to proliferate after an increase in the quantity of organic matter, have played an especially important role in impacted softbottom habitats [26]. Macrobenthic data collected during the present study have shown macrobenthic community assemblages in Laizhou Bay distinct from those in 1982, suggesting that the soft-sediment habitats might have been disturbed or polluted in the past three decades.

Clustering and MDS clearly showed significant differences in the community structure of the macrobenthos at different sites (Fig. 2). Therefore, to explore the manner of macrobenthic community at different stations is meaningful and can be used to evaluate the relationship between these differences and various physical disturbances of sediment and heavy-metal pollutions. There was greater divergence between the third site (S3) and the other stations. Station S3 was the station nearest to the Yellow River estuary, which was only $20.62 \mathrm{~km}$ away. It is well known that estuaries are particularly challenging to study because of strong spatial, seasonal and interannual variations of environmental characteristics that influence macrobenthic community [27]. According to the present study, the numbers of species were very low at station S3 $(7,12$, and 1 in spring, summer, and autumn, respectively. The low diversity and numbers of macrobenthic organisms are estuarine characteristics as compared to those of fresh water or marine [28].

\subsection{Assessment of macrobenthic community health}

Laizhou Bay is a complex transitional environment between terrestrial and marine ecosystems that also supports industrial activities, salt-extraction, and aquaculture [13]. Interpreting the effects of disturbance is complex with the assessment of natural or anthropogenic impacts on macrobenthic integrity. Because of their fine grain size, the sediments of Laizhou Bay are efficient accumulators of contaminants, functioning as an indicator of contamination and playing a basic role in the bioavailability of some compounds. Therefore, it is very important to assess the ecological quality status of Laizhou Bay based on the composition and distribution of the macrobenthic community.

Monitoring of polychaete families has proven to be a suitable tool for rapid assessment of anthropogenic impacts [29]. The ABC plots for Laizhou Bay showed that the biomass curves lay below the abundance curves, and the $W$-statistic value was negative (Fig. 3). In the disturbed environment, $r$-selected species (fast-growing, small, opportunistic) represented a large proportion of the macrobenthic community [18]. Therefore, the trend revealed by the $\mathrm{ABC}$ plot supported the conclusion that Laizhou Bay was in an ecologically unhealthy condition.

The BOPA index is appropriate for surveying the temporal changes of macrobenthic systems at high frequencies, and it can be applied to assign estuarine and coastal ecological quality statuses to five levels [20]. The fossorial amphipod Ampelisca diadema builds and irrigates its burrow or tube in previously anoxic sediment, thereby creating a small oxidized cylinder within the sediment that promotes seabottom oxygenation and nitrification processes. Therefore, it has been termed a facilitator in structuring the community [30]. Opportunistic polychaete species are selected in relation to their ability to proliferate after increases in the supply of organic matter, so they are pioneer forms dominating the initial stages of succession after disturbance [26]. Low colonization by amphipods and abundance of opportunistic polychaetes were observed at the polluted sites in Laizhou Bay. The BOPA index showed that two stations had moderate ecological status in spring, and there were two heavily and one moderately polluted sites in summer (Fig. 4). In summer, there was a very high abundance of the opportunistic species Heteromastus filiforms at stations S04 and S02, which were near the Yellow River estuary. This has been considered a typical estuarine species [22]. It seems that the Yellow River has a great influence on the composition and structure of the macrobenthos in the estuary of Laizhou Bay.

\subsection{Influence of physical and chemical characteristics of sediments}

Analysis of the correlations between the macrobenthic community and physical and chemical characteristics of sediments for all the stations yielded high values of the rank correlation coefficient $\left(\rho_{\mathrm{s}}>0.4\right.$ for the best single correlated variable and $\rho_{\mathrm{s}}>0.8$ for the best-correlated variable combination), suggesting that physical and chemical characteristics of the sediments played important roles in affecting the macrobenthic community structure in Laizhou Bay. Separate analyses of correlation showed there were differences in the best-correlated variable combinations in different seasons. The BIO-ENV index indicated that grain size fractions and trace metals ( $\mathrm{Hg}, \mathrm{Pb}, \mathrm{Zn}, \mathrm{Cu}$, and $\mathrm{Cr}$ ) were best matches to affect macrobenthic community structure. Previous studies have demonstrated that sediment grain size served as the dominant factor defining macrobenthic assemblages [31].

A trace amount of metals is essential for providing the micronutrients necessary for the growth of many marine organisms [32]. However, excessive amounts of heavy metals enter the coastal environment via anthropogenic industrial activities, mining activities, agriculture (run-off), and sewage disposal [33, 34], are considered toxic and restrain the growth and propagation of macrobenthic organisms [35-37]. Rygg has found negative correlations between species diversity in macrobenthic community and copper concentrations and organic matter [38]. McLusky et al. [39] also showed that higher concentrations of $\mathrm{Cu}$ were toxic to macrobenthos and lowered their diversity. The higher concentrations of metals $(\mathrm{Zn}, \mathrm{Cu}, \mathrm{Pb}$, and $\mathrm{Cr}$ ) seem to become the polluting and even toxic to the macrobenthos [28]. In the present study, the BIO-ENV analyses indicated that the grain size fractions together with trace metals $(\mathrm{Hg}, \mathrm{Pb}, \mathrm{Zn}, \mathrm{Cu}$, and $\mathrm{Cr}$ ) were the major environmental variables influencing the macrobenthic patterns. The results together demonstrated that the macrobenthic communities in Laizhou Bay were negatively affected, perhaps by the tremendous impact of heavy metals in the sediments.

\section{Acknowledgments}

The authors were grateful to all the laboratory members for continuous technical advice and helpful discussion. This project was 
financially supported by Shandong Province Natural Science Fund Committee grant no.: ZR2011CQ017 and Key Laboratory of Coastal Zone Environmental Processes and Ecological Remediation, YICCAS grant no.: 201202 to Dr. Ying Zhang. This research was also supported by Taishan Scholar position of aquatic animal nutrition and feed, National Marine Public Welfare Research Project (200905019). We would like to thank the editor and the two anonymous reviewers for their helpful comments.

The authors have declared no conflict of interest.

\section{References}

[1] L. Lu, The Relationship between Soft-Bottom Macrobenthic Community and Environmental Variables in Singaporean Waters, Mar. Pollut. Bull. 2005, 51 (8-12), 1034-1040.

[2] G. R. Bilyard, The Value of Benthic Infauna in Marine Pollution Monitoring Studies, Mar. Pollut. Bull. 1987, 18 (11), 581-585.

[3] D. M. Dauer, Biological Criteria, Environmental Health and Estuarine Macrobenthic Community Structure, Mar. Pollut. Bull. 1993, 26 (5), 249-257.

[4] P. Guidetti, M. Modena, G. L. Mesa, M. Vacchi, Composition, Abundance and Stratification of Macrobenthos in the Marine Area Impacted by Tar Aggregates Derived from the Haven Oil Spill (Ligurian Sea, Italy), Mar. Pollut. Bull. 2000, 40 (12), 1161-1166.

[5] H. Hampel, M. Elliot, A. Cattrijsse, Macrofaunal Community in the Habitats of Intertidal Marshes along the Salinity Gradient of the Shelde Esturary, Estuaries Coastal Shelf Sci. 2009, 84 (1), 45-53.

[6] K. Obolewski, K. Glińska-Lewczuk, Effects of Oxbow Reconnection based on the Distribution and Structure of Benthic MacroInvertebrates, Clean - Soil Air Water 2011, 39 (9), 853-862.

[7] C. J. Calabretta, C. A. Oviatt, The Response of Benthic Macro-Fauna to Anthropogenic Stress in Narragansett Bay, Rhode Island: A Review of Human Stressors and Assessment of Community Conditions, Mar. Pollut. Bull. 2008, 56 (10), 1680-1695.

[8] J. L. Goméz-Gesteira, J. C. Dauvin, Amphipods are Good Bioindicators of the Impact of Oil Spills on Soft-Bottom Macrobenthic Community, Mar. Pollut. Bull. 2000, 40 (11), 1017-1027.

[9] G. Kanaya, E. Kikuchi, Spatial Changes in a Macrozoobenthic Community along Environmental Gradients in a Shallow Brackish Lagoon Facing Sendai Bay, Jpn. Estuaries Coastal Shelf Sci. 2008, 78 (4), 674-684.

[10] A. Cosentino, S. Giacobbe, Distribution and Functional Response of Sublittoral Soft Bottom Assemblages to Sedimentary Constraints, Estuaries Coastal Shelf Sci. 2008, 79 (2), 263-276.

[11] A. Nanami, H. Saito, T. Akita, K. Motomatsu, H. Kuwahara, Spatial Distribution and Assemblage Structure of Macrobenthic Invertebrates in a Brackish Lake in Relation to Environmental Variables, Estuaries Coastal Shelf Sci. 2005, 63 (1-2), 167-176.

[12] D. C. Rhoads, Organism-Sediment Relationships on the Muddy Sea Floor, Oceanogr. Mar. Biol. Ann. Rev. 1974, 12, 263-300.

[13] R. J. Etter, J. F. Grassle, Patterns of Species Diversity in the Deep Sea as a Function of Sediment Particle Size Diversity, Nature 1992, 360 (10), 576-578.

[14] Y. Zhang, Y. J. Liu, Y. Zhang, B. Q. Xu, Z. B. Lv, Ecological Characteristics of Benthic Polychaete Community and Its Response to Environmental Change in Laizhou Bay, Shandong Province of East China, Chin. J. Ecol. 2012, 31 (15), 781-786.

[15] E. Kristensen, F. Ä. Anderson, Determination of Organic Carbon in Marine Sediments: A Comparison of Two CHN-Analyser Methods, J. Exp. Mar. Biol. Ecol. 1987, 109 (1), 15-23.

[16] A. P. Mucha, M. Vasconcelos, A. A. Bordalo, Vertical Distribution of the Macrobenthic Community and Its Relationships to Trace Metals and Natural Sediment Characteristics in the Lower Douro Estuary, Portugal, Estuaries Coastal Shelf Sci. 2004, 59 (4), 663-673.
[17] K. R. Clarke, R. M. Warwick, Change in Marine Community: An Approach to Statistical Analysis and Interpretation, 2nd Ed., PRIMER-E, Plymouth 2001.

[18] T. V. Joydas, P. K. Krishnakumar, M. A. Qurban, S. M. Ali, A. AlSuwailem, K. Al-Abdulkader, Status of Macrobenthic Community of Manifa-Tanajib Bay System of Saudi Arabia Based on a Once-Off Sampling Event, Mar. Pollut. Bull. 2011, 62 (6), 1249-1260.

[19] R. M. Warwick, A New Method for Detecting Pollution Effects on Marine Macrobenthic Community, Mar. Biol. 1986, 92 (4), 557-562.

[20] J. C. Dauvin, T. Ruellet, Polychaete/Amphipod Ratio Revisited, Mar. Pollut. Bull. 2007, 55 (1-6), 215-224.

[21] J. Patrício, J. M. Neto, H. Teixeira, F. Salas, J. C. Marques, The Robustness of Ecological Indicators to Detect Long-Term Changes in the Macrobenthos of Estuarine Systems, Mar. Environ. Res. 2009, 68 (1), 25-36.

[22] Z. Chen, J. Wang, Z. Wang, D. Xia, R. Dai, Y. Bao, Z. Dou, et al., Chinese Embayment (Part 3), China Ocean Press, Beijing 1991, pp. 71-73.

[23] R. N. Zajac, R. B. Whitlatch, Response of Estuarine Infauna to Disturbance, II. Spatial and Temporal Variation of Succession, Mar. Ecol. Prog. Ser. 1982, 10, 15-27.

[24] P. L. McCall, PhD Thesis, Yale University, New Haven, CT 1975, p. 198.

[25] R. B. Whitlatch, R. M. Zajac, Biotic Interactions among Estuarine Infaunal Opportunistic Species, Mar. Ecol. Prog. Ser. 1985, 21, 299-311.

[26] A. Giangrande, M. Licciano, L. Musco, Polychaetes as Environmental Indicators Revisited, Mar. Pollut. Bull. 2005, 50 (11), 1153-1162.

[27] P. Chainho, J. L. Costa, M. L. Chave, D. M. Dauer, M. J. Costa, Influence of Seasonal Variability in Benthic Invertebrate Community Structure on the Use of Biotic Indices to Assess the Ecological Status of a Portuguese Estuary, Mar. Pollut. Bull. 2007, 54 (10), 1586-1597.

[28] J. Dauvin, Effects of Heavy Metal Contamination on the Macrobenthic Fauna in Estuaries: The Case of the Seine Estuary, Mar. Pollut. Bull. 2008, 57 (1-5), 160-169.

[29] Y. Del-Pilar-Ruso, J. A. de-la-Ossa-Carretero, F. Giménez-Casalduero, Sewage Treatment Level and Flow Rates Affect Polychaete Assemblages, Mar. Pollut. Bull. 2010, 60, (11), 1930-1938.

[30] A. Occhipinti-Ambrogi, D. Savini, G. Forni, Macrobenthos Community Structural Changes Off Cesenatico Coast (Emilia Romagna, Northern Adriatic), a Six Year Monitoring Programme, Sci. Total Environ. 2005, 353 (1-3), 317-328.

[31] H. L. Sanders, Benthic Studies in Buzzards Bay, I. Animal-Sediment Relationships, Limnol. Oceanogr. 1958, 3 (3), 245-258.

[32] X. Wang, H. Feng, H. Ma, Assessment of Metal Contamination in Surface Sediments of Jiaozhou Bay, Qingdao, China, Clean - Soil Air Water 2007, 35 (1), 62-70.

[33] O. I. Davutluoglu, G. Seckin, C. B. Ersu, T. Yilmaz, B. Sari, Assessment of Metal Pollution in Water and Surface Sediments of the Seyhan River, Turkey, Using Different Indexes, Clean - Soil Air Water 2011, 39 (2), 185-194.

[34] H. Zhang, B. Cui, K. Zhang, Surficial and Vertical Distribution of Heavy Metals in Different Estuary Wetlands in the Pear River, South China, Clean - Soil Air Water 2012, 40 (10), 1174-1184.

[35] R. Xiao, J. Bai, H. Gao, J. Wang, L. Huang, P. Liu, Distribution and Contamination Assessment of Heavy Metals in Water and Soils from the College Town in the Pearl River Delta, China, Clean - Soil Air Water 2012, 40 (10), 1167-1173.

[36] K. Y. Hwang, H. S. Kim, I. Hwang, Effect of Resuspension on the Release of Heavy Metals and Water Chemistry in Anoxic and Oxic Sediments, Clean - Soil Air Water 2011, 39 (10), 908-915.

[37] L. Huang, J. Bai, R. Xiao, H. Gao, P. Liu, Spatial Distribution of Fe, Cu, $\mathrm{Mn}$ in the Surface Water System and Their Effects on Wetland Vegetation in the Pearl River Estuary of China, Clean - Soil Air Water 2012, 40 (10), 1085-1092.

[38] B. Rygg, Effect of Sediment Copper on Benthic Fauna, Mar. Ecol. Prog. Ser. 1985, 25, 83-89.

[39] D. S. McLusky, V. Bryant, R. Campbell, The Effects of Temperature and Salinity on the Toxicity of Heavy Metals to Marine and Estuarine Invertebrates, Oceanogr. Mar. Biol. 1986, 24, 481-520. 